\title{
Microstructural Effects on Fatigue Crack Growth of Cast and Forged TiAl Alloys
}

\author{
D.R. Clemens*, C.I. Lobo* \\ \& D.L. Anton \\ * Pratt \& Whitney, W. Paim Beach, FL \\ United Technologies Research Ctr., E. Hartford, CT
}

\begin{abstract}
Fatigue crack growth and tensile experiments were conducted on three TiAl alloys in the cast duplex 47-XD, cast nearly fully lamelar 45-XD and wrought fully lamellar $47-5$ at 25 and $650^{\circ} \mathrm{C}$. The microstructures were fully characterized defining the extent of lamelar colony size. lath spacing presence of other phases. The tensile experiments showed the two lamellar structures to be stronger while the duplex alloy maintained a significantly higher fracture toughness at elevated temperatures. Fatigue crack growth threshold tests showed negligible difference between the three alloys and microstructures, having a $\mathrm{K}_{\mathrm{th}}=6$ to $8 \mathrm{ksi}$ in. The need is exposed for an altemate failure design criteria to take advantage of $\gamma$ TiAl, where low densities and high threshold stress intensities hold advantage in light weight and durability not attainable in conventional nickel base alloys.
\end{abstract}

\section{Introduction}

Titanium aluminides based on the $\gamma$ phase TiAl are being seriously considered for various applications in aero gas turbine engines. One serious consideration in implementation of these alloys is their low ductility and damage tolerance. Before consideration can be given to their implementation in highly stressed flight critical applications such as compressor or turbine blades, vanes or disks; a thorough understanding of flaw growth characteristics will need to be attained.

In spite of this urgent requirement, relatively little attention has been given to the microstructural factors affecting fatigue crack growth in these complex alloys. A number of reviews have focused on the microstructural influences on tensile properties and fracture toughness [1. 3]. These studies of fatigue crack growth characteristics in $\gamma$-TiAl have concentrated on either the duplex or fully lamellar structures without directly comparing the two [4-10]. Recent results have shown that the fully lamellar structures are more resistant to fatigue crack growth, especially at lower stress intensities, than the duplex microstructures [57]. The orientation of the lamellar colony with respect to the crack plane was found to play a strong role in crack growth rate. Trans-lamellar cracks were observed to propagate rapidly between lamellae only to stop and blunt at lamellar interfaces [5]. Those cracks which ran along lamellar interfaces propagated at a much more rapid rate. Fatigue crack closure was found to be minimal under ambient conditions and more significant at elevated temperatures due to oxidation induced closure $[4,6]$.

A study is described here, which begins to fulfill the requirement of investigation and characterization of fatigue crack growth and fracture in two cast and one forged $\gamma$ alloys being considered for rotating aircraft engine components. Through observation of fracture and fatigue crack growth characteristics with $\gamma$-TiAl microstructural variations, a clearer understanding of the influence of these factors are obtained.

\section{Design Criteria \\ Fracture}

For current materials, fracture critical components are designed and life managed under the Engine Structural Integrity Program (ENSIP) program which requires the damage tolerance of materials with respect to intrinsic or service generated defects must be demonstrated. This typically involves using an inspectable flaw size (determined by NDE) and calculated stress levels to determine remaining fracture (crack growth) life. This life is then used to set an inspection interval. However, for britle materials, there is a narrow interval between the threshold stress intensity, $\Delta K_{l_{b}}$ and the fracture toughness, $K_{I C}$, the crack growth rate curves are extremely steep, especially at room temperature [11]. Thus, the fraction of total design life resulting from crack propagation is small, and the inspection intervals, if any, are too frequent to be practical.

As a result, a new method of addressing ENSIP for brittle materials might be required, such as the use of $\Delta K_{\mathrm{th}}$ as a life prediction criteria. In such a case, the scrvice loads would have to be kept below Kth for a given initial flaw size to prevent the rapid propagation to failure of cracks initiated at flaws [7]. Designing below threshold would theoretically result in infinite life ( $>10^{3}$ cycles), thus eliminating the need for design intervals.

\section{Fatigue}

For current materials, Low Cycle Fatigue (LCF) is also managed under the auspices of the ENSIP program. I ow cycle fatigue is generally caused by engine start/stop or throttle cycles which occur at low frequency. Crack initiation is defined as a $1 / 32 "(1 \mathrm{~mm})$ long surface crack. P\&W and the USAF define the acceptable probability of occurrence of an LCF crack as 1 crack occurring in a sample size of 1000 (1/1000 or B.1) having a 1/32" $(1 \mathrm{~mm})$ long crack at the predicted minimum life. Stress vs. life data can be regressed with a variety of equations; one of the most popular is the strain range/mean stress design system approach. This current approach covers a wide range of stress concentrations, temperature effects, stress ratios and the mean stress shift due to yielding. These methods, however, are geared to data which exhibits the following: low cycles to failure at high stresses and high cycles to failure at low stresses. Usually, an endurance limit approach, such as is popular with HCF, is avoided as too conservative. Data may exhibit some degree of scatter at individual stress levels, but not excessively. With the brittle gamma though, the data is relatively flat (high stresses result in few to many life cycles) and exhibits material scatter than scans 4 orders of magnitude (Figure 1).

As a result, new methods of addressing ENSIP for brittle materials in LCF might be required. In particular, similar to the crack growth rate case of designing below the threshold stress intensity, an LCF design system might involve designing to below an endurance stress limit. In this method, one would still design to a 3 sigma minimum endurance limit, and this would hopefully be considered a 'safe' limit. However, in reality, since the gamma LCF curves are so flat, and especially since there 


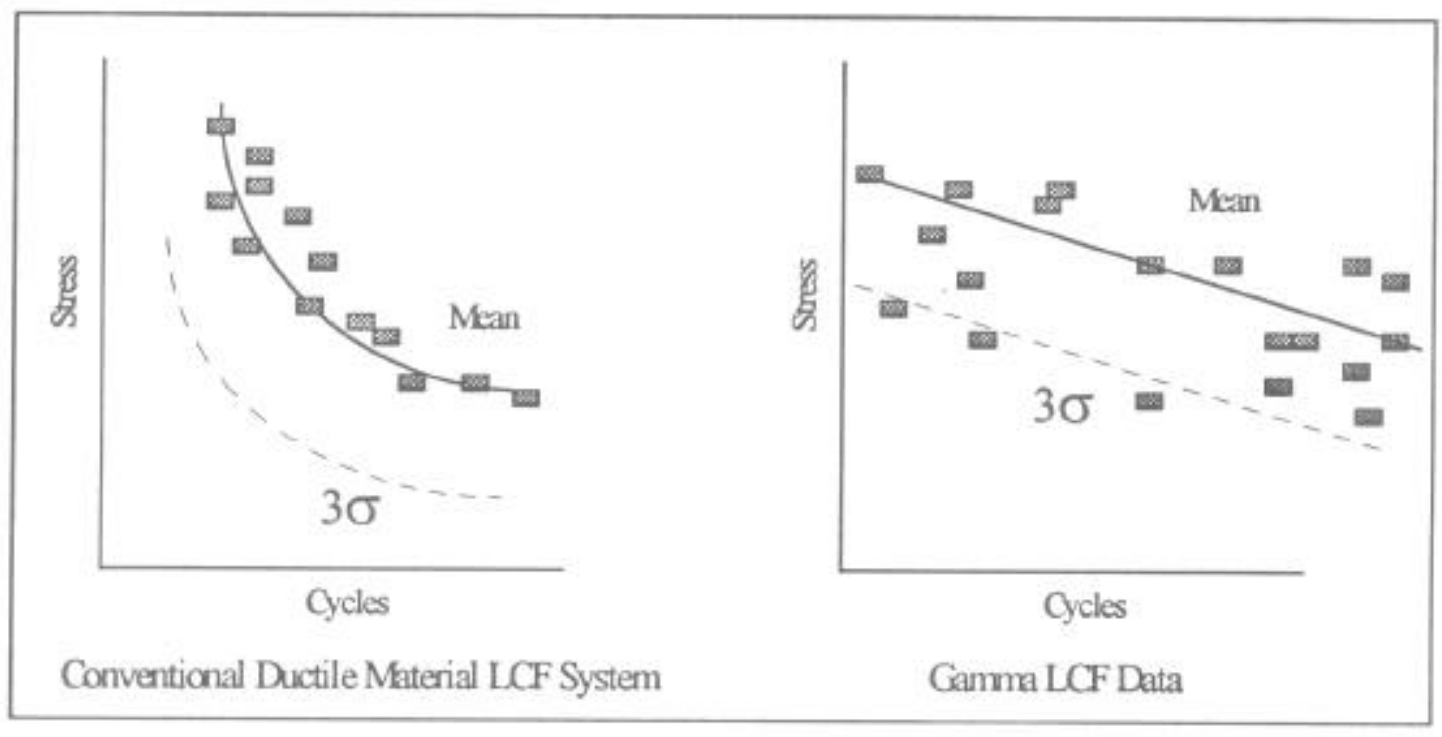

Fig. 1 Gamma LCF date vs. conventional design methods.

is a wide amount of scatter in life with very little difference in stress, the endurance limit approach might not be conservative enowgh if there's only limited testing as is currently the case. Also in the endurance limit approach, there is a risk of being too conservative in the high stress, low life area, which might reduce the weight advantages of using gamma.

\section{Experimental Procedures}

Three alloys were selected for study': 47-XD ( $\mathrm{Ti}, 47 \mathrm{Al}, 2 \mathrm{Mn}, 2 \mathrm{Nb}$, $0.8 \mathrm{~B}), 45-\mathrm{XD}(\mathrm{Ti}, 45 \mathrm{Al}, 2 \mathrm{Mn}, 2 \mathrm{Nb}, 0.8 \mathrm{~B})$ and $47.5(\mathrm{Ti}, 47 \mathrm{Al}, 2 \mathrm{Cr}$, $2 \mathrm{Nb}, 0.8 \mathrm{~B}$ ). The $\mathrm{XD}$ alloys are investunent cast alloys which were HIP'ed to close casting porosity in the $\alpha^{\prime} \gamma$ two phase region and stabilized in the $\alpha_{\gamma} / \gamma$ two phase region. The 47.5 alloy was two step forged and solution heat treated in the $\alpha$ region and stabilized in the $\alpha_{2} y$ two phase region.

The microstructures were characterized under both optical and SEM microscopy to determine grain size, and $\alpha_{2} / \gamma$ lathe spacing and grain boundary configuration. Preliminary tensile tests were conducted in air at ambient and $650 \mathrm{C}$ to guide FCG loading Fatigue specimens were machined in a compact tension configuration. Fatigue crack growth tests were conducted in a servo-hydraulic testing machine using an R-ratio of 0.1 at $20 \mathrm{~Hz}$ at ambient and $650 \mathrm{C}$. Fatigue crack growth measurements were made optically. The fracture surfaces were characterized utilizing SEM and crack propagation features correlated with stress intensity factor.

\section{Results and Discussion}

\section{Microstructural Characterization}

Results of the metallographic examination are sumanarized in Table 1. The 47-XD alloy contained a duplex microstructure, DP, consisting of both single phase $\gamma$ grains as well as grains composed of $\alpha_{\nu} \gamma$ lathes. The lathe grains composed approximately $40 \%$ of the structure and were 100 $\mu \mathrm{m}$ in diancter while the single phase $\gamma$ grains were $30-50 \mu \mathrm{m}$ in diameter and dispersed among the lathe colonies. Along with these two majority phases, a fine dispersion of borides was observed uniformly distributed turough out the structure. These borides took on three morphologies, discrete (0.1-0.3 $\mu \mathrm{m}$ in diancter), filamentary $(1 \times 0.05$ $\mu \mathrm{m})$ and blocky (ranging as large as $1 \times 5 \mu \mathrm{m})$. Fig, 2 gives a typical view of this microstructure. The $45-\mathrm{XD}$ specimens were nearly fully lamellar microstructure, NFL, having a grain size of $50 \mu \mathrm{m}$. A fow single phase $\gamma$ grains were observed, but they composed less than $5 \%$ of the materials volume and were on the order of $10 \mu \mathrm{m}$ in diameter. The borides were all either discrete or filamentary in these specimens, on the same order in size as those in the 47-XD alloy, with no blocky borides found Fig 3 is an optical micrographs of this alloy detailing boride distribution. The 47.5 alloy is shown in Fig. 4 . Here the grains range from $200 \mu \mathrm{m}$. The microstructure is in the fully lamelar, FL, form. The borides in this alloy were descrete to acicular and having dimensions ranging from $1 \times 1$ to $1 \times 6 \mu \mathrm{m}$. Additionally, a number of boride stringers, remnant from forging and clearly visible in Fig. 4, were found throughout the structure.

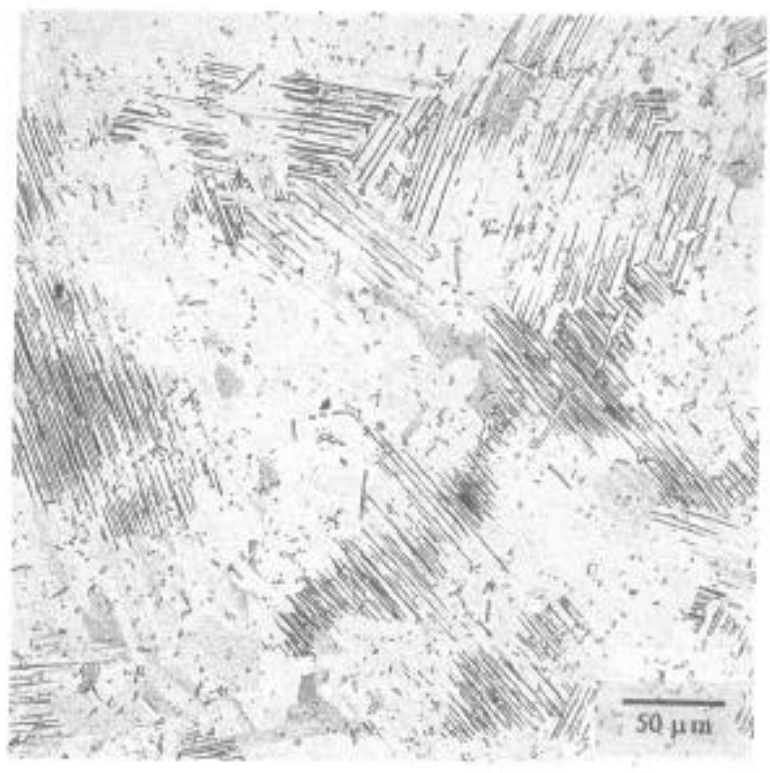

Fig. 2 Micrograph of 47-XD alloy showing the duplex cast microstructure of single phase $\gamma$ grains with $\alpha_{y} / \gamma$ lathe coloties, along with filamentary and discrete borides.

Tensile and Fatigue Crack Growth Testing

The results of tensile and fatigue crack growth threshold results are given in Table II. Under tensile conditions the 45-XD alloy is considerably stronger than either the cast $47-\mathrm{XD}$ or the wrought 47.5 alloys. 


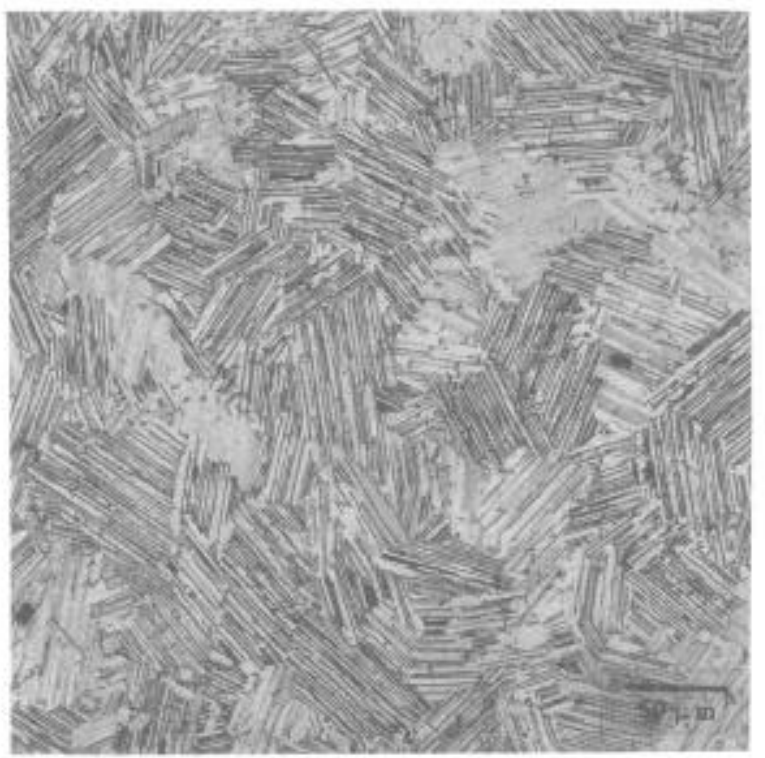

Fig. 3

Micrograph of 45-XD alloy showing the nearly fully lamellar cast microstructure of with $\alpha_{y} / y$ lathe colonies with only small remuants of single phase $\gamma$ grains, along with filamentary and discrete borides.

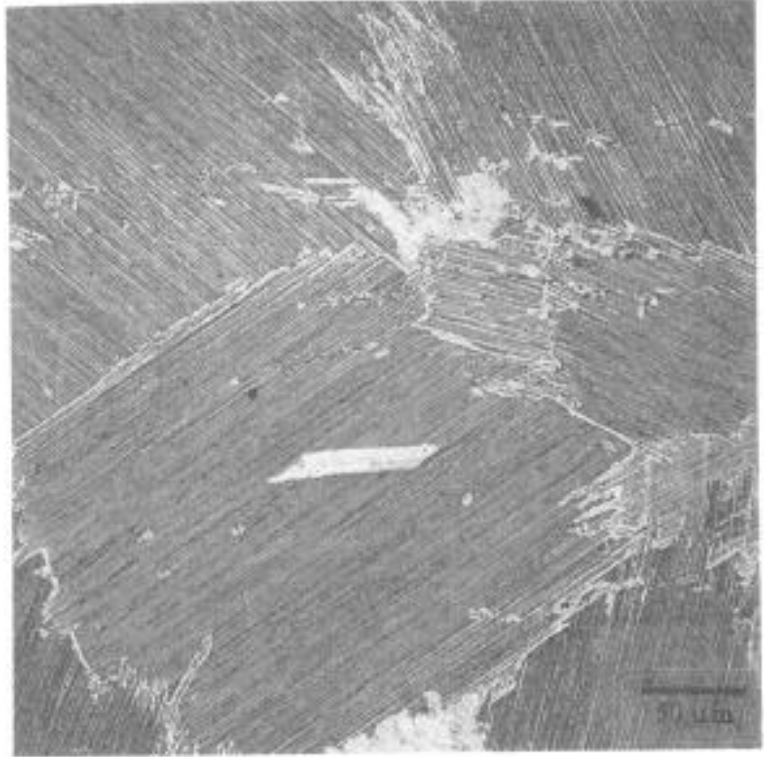

Fig. 4 Micrograph of 47-5 alloy showing the nearly fully lamellar wrought microstructure of with $\alpha_{2} / \gamma$ lathe colonies with only small remnants of single phase $\gamma$ grains, along with diserete and blocky borides.

Table I Summary of Alloy Microstructures

\begin{tabular}{|c|c|c|c|c|c|c|c|c|}
\hline Alloy & Micro. & $\begin{array}{l}\text { Vol. \% } \\
\text { Lathe }\end{array}$ & 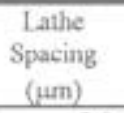 & $\begin{array}{l}\text { Lathe GS } \\
(\mu \mathrm{m})\end{array}$ & 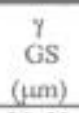 & $\begin{array}{l}\text { Discr. } \\
\text { ( } \mu \mathrm{m})\end{array}$ & $\begin{array}{c}\text { Boride } \\
\text { Filament } \\
(\mu \mathrm{m})\end{array}$ & $\begin{array}{l}\text { Blocky } \\
(\mu \mathrm{m})\end{array}$ \\
\hline $47 . X \mathrm{X}$ & $\overline{D P}$ & $40 \%$ & 2.0 & 100 & $30-50$ & $0.1-0.3$ & $1 \times 0.5$ & 1.5 \\
\hline $45-X D$ & NFL. & $>95 \%$ & 3.0 & 50 & 10 & $0.1-0.3$ & $1 \times 0.5$ & \\
\hline $47-5$ & $\mathrm{FL}$ & $100 \%$ & 0.5 & 200 & & & $6 \times 1$ & \\
\hline
\end{tabular}

Surprisingly, both east alloys displayed higher elongation than the wroughit alloy. Threshold stress intensity for all of these alloys was comparable at 25 and $650^{\circ} \mathrm{C}$, with the wrought alloy displaying a slightly enhanced resistance to slow crack growth at ambient conditions. Fatigue crack growth curves represented as da/dn vs. $\Delta K$ are given for these three alloys at 25 and $650^{\circ} \mathrm{C}$ in Figs. 5.7.

Alloy $45-\mathrm{XD}$, a NFL structure, maintained significantly grtater yield and ultimate strengths than either of the other alloys in the conditionis tested. This was followed by the FL 47.5 alloy in strength at all but the $650^{\circ} \mathrm{C}$ ultimate strength where the NFL 47.5 and DP 47.XD alloys were comparable. These results are consistent with data reported in the literature $[12-14]$ which have shown that, fully tameilar structures can maintain strengths approaching and surpassing duplex material, if the grain size is maintained below 500-1000 um. If, however, the NFL, and FL lamellar colony size is minimized, tensile strength and ductility are enhanced. The addition of boron to these cast alloys is known to minimized grain growth to a large extent and resulted in a relatively fine grain, 50 to $200 \mathrm{pm}$, fully lamellar structure.

As expected, the fully lamellar 47-5 alloy displayed a lower strain to failure at both ambient and elevated temperatures than the two cast alloys, due to its some what larger grain size.

Cyclic fracture toughness for the three alloys and microstructures studied here wete conparable under ambient conditions; while the 47-XD alloy in the duplex mictostructure displayed a near doubling in toughness at $650^{\circ} \mathrm{C}$ to nearly $20 \mathrm{ksivin}$. The FL and NFL alloys (alloys 47.5 and 45 . $\mathrm{XD}$ respectively) maintained a moderate fracture toughuess of approximately $10-13 \mathrm{ksivin}$, consistent with the literature values of other alloys in the NFL and FL. structure $[1,2]$.

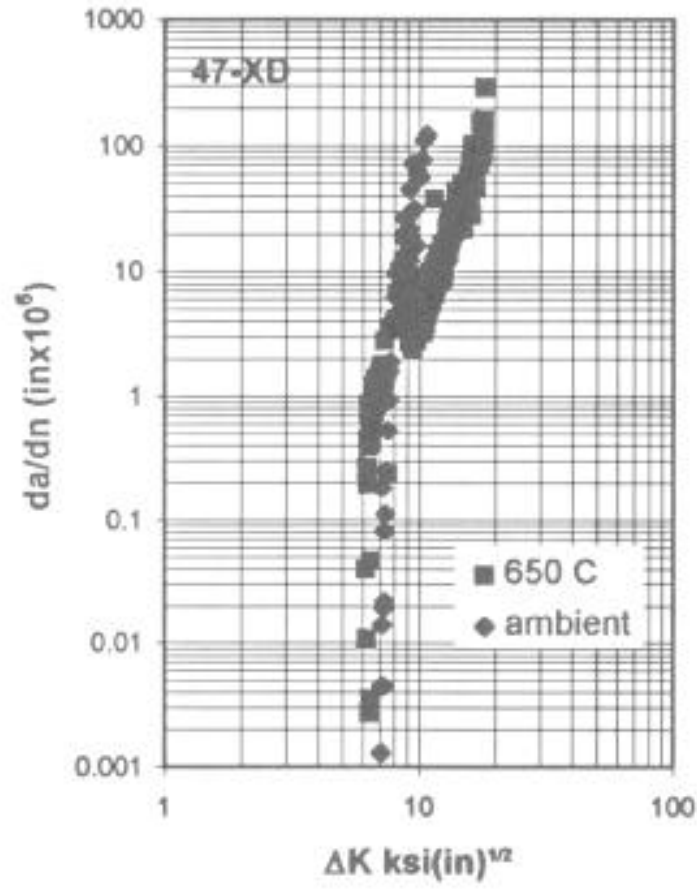

Fig. 5 da/den carve for allioy $47-\mathrm{XD}$ at $25^{\circ} \mathrm{C}$ and $650^{\circ} \mathrm{C}$. 


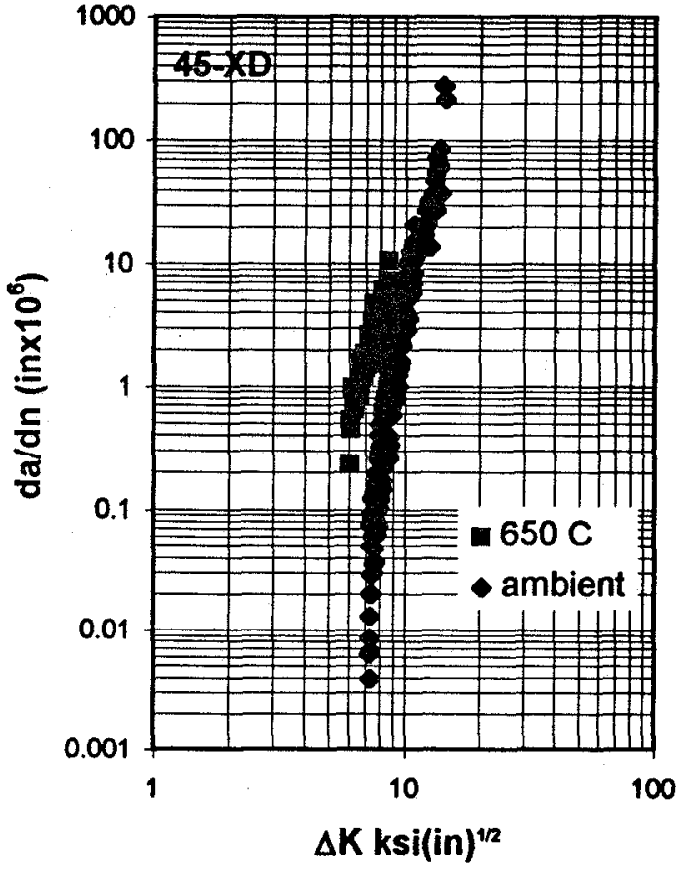

Fig. $6 \mathrm{da} / \mathrm{dn}$ curve for alloy $45-\mathrm{XD}$ at $25^{\circ} \mathrm{C}$ and $650^{\circ} \mathrm{C}$.

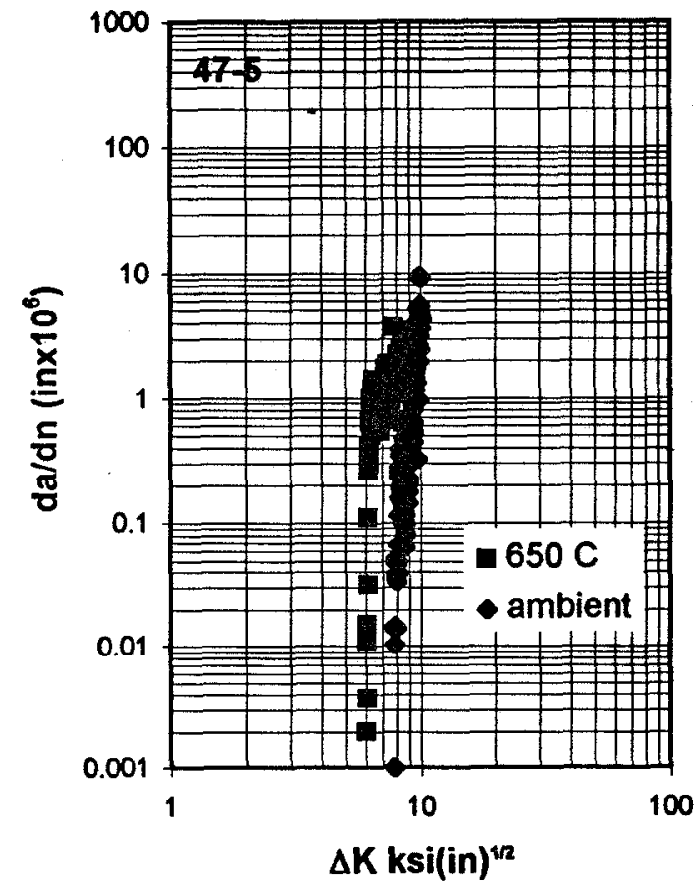

Fig. $7 \mathrm{da} / \mathrm{dn}$ curve for alloy $47-5$ at $25^{\circ} \mathrm{C}$ and $650^{\circ} \mathrm{C}$.

Table II Tensile and Fatigue Crack Growth Threshold Results

\begin{tabular}{|c|c|c|c|c|c|c|}
\hline Alloy & $\begin{array}{l}\text { Temp. } \\
\left({ }^{\circ} \mathrm{C}\right)\end{array}$ & $\begin{array}{l}\text { Yield } \\
\text { Stress } \\
\text { (ksi) }\end{array}$ & $\begin{array}{c}\text { Ultimate } \\
\text { Stress } \\
\text { (ksi) }\end{array}$ & $\begin{array}{c}\text { Failure } \\
\text { Strain } \\
(\%) \\
\end{array}$ & $\begin{array}{c}\text { Fracture } \\
\text { Toughness } \\
\text { (ksivin.) }\end{array}$ & $\begin{array}{l}\text { Threshold Stress } \\
\text { Intensity } \\
\text { (ksivin.) }\end{array}$ \\
\hline 47-XD & 25 & 57 & 73 & 1.3 & 10 & 7.5 \\
\hline $47-\times D$ & 650 & 49 & 75 & 3.9 & 19 & 6.5 \\
\hline 45-XD & 25 & 85 & 100 & 1.5 & 13 & 7.3 \\
\hline $45-\times D$ & 650 & 70 & 96 & 2.8 & 9 & 6.2 \\
\hline $47-5$ & 25 & 65 & 83 & 0.8 & 10 & 7.9 \\
\hline $47-5$ & 650 & 62 & 74 & 0.8 & 9 & 6.2 \\
\hline
\end{tabular}

The threshold stress intensity was very consistent between the these three alloys. At ambient temperatures, where little closure is anticipated, $\Delta K_{\text {th }}$ ranged between 7.3 and $7.9 \mathrm{ksi}$ in. At elevated temperature, where closure due to oxidation of the crack tip has been observed [4], $\Delta K_{\text {th }}$ ranged between 6.2 and $6.5 \mathrm{ksi}$ in. The literature has indicated the fully lamellar structure to be more resistant to crack growth than the duplex structure [8]. This was not observed here, and may be attributed to the larger grain sizes, approximately $400 \mu \mathrm{m}$, tested in [8] for the fully lamellar structure. This is somewhat surprising given the wide differences in processing and microstructure. Other researchers have shown substantial differences in $\mathrm{K}_{\mathrm{th}}$ dependent on microstructure [7].

\section{Fractography}

Four of the failed compact tension (CT) fatigue crack growth specimens were selected for fractographic examination. The specimens were examined at crack lengths yielding approximately equal stress intensities. The specimens are described in the Table III. The fractographic comparisons of 47-XD alloy provide information about the effects of temperature. The three room temperature fracture examinations provide information about the effect of alloy/microstructure/thermal mechanical processing on microscopic fracture mode.

The 47-XD alloy microstructure was clearly mirrored in the fracture topology. Some of the fine grains exhibited a lamellar structure, and others showed no apparent structure. The later grains are assumed to be equiaxed $\gamma$ grains. At $26^{\circ} \mathrm{C}$, these fine grained areas occasionally exhibited intergranular fracture (see Fig. 8a). The large lamellar colonies invariably showed transgranular fracture, either translamellar, interlamellar or both in combination [7]. Fig. 8b highlights the details of translamellar crack growth. Intralamellar crack branching is evident (at the center of Fig. $8 \mathrm{~b}$ and running into the plane of the photo). Secondary cracking produced a serrated appearance suggesting crystallographic slip/fracture.

Table III Specimens Selected for Fractographic Analysis

\begin{tabular}{|cccc|}
\hline Alloy & $\begin{array}{c}\text { Temp. } \\
\left({ }^{\circ} \mathrm{C}\right)\end{array}$ & $\begin{array}{c}\text { da/dn } \\
\text { (in./cycle) }\end{array}$ & $\begin{array}{c}\Delta K \\
\text { (ksi } \sqrt{\text { in. }})\end{array}$ \\
\hline $47-\mathrm{XD}$ & 26 & $2 \times 10^{-5}$ & 10 \\
$47-\mathrm{XD}$ & 650 & $4 \times 10^{-6}$ & 10 \\
$45-\mathrm{XD}$ & 26 & $4 \times 10^{-6}$ & 10 \\
$47-5$ & 26 & $4 \times 10^{-6}$ & 10 \\
\hline
\end{tabular}




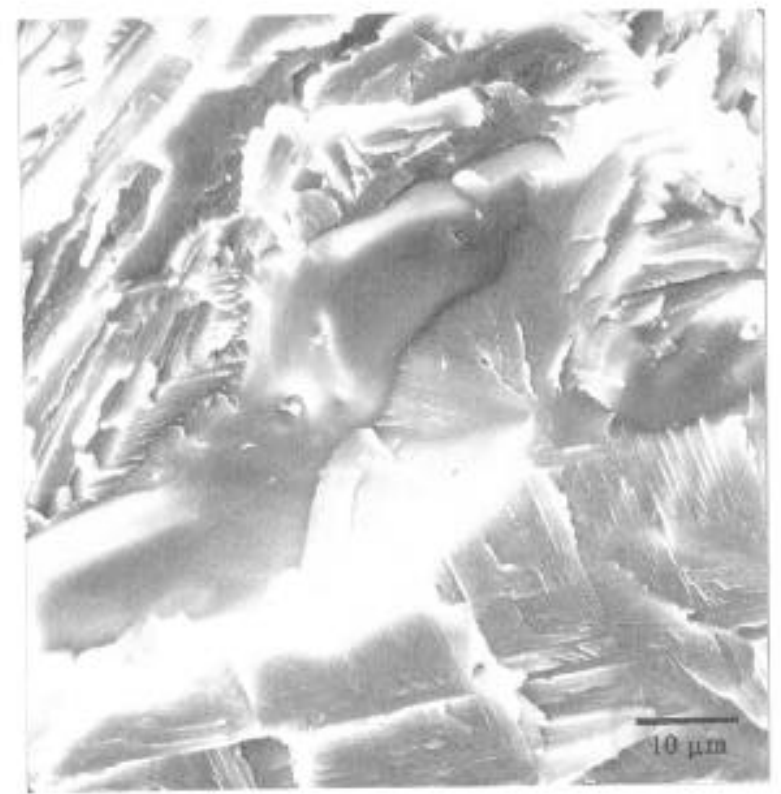

(a)

Fig. 8

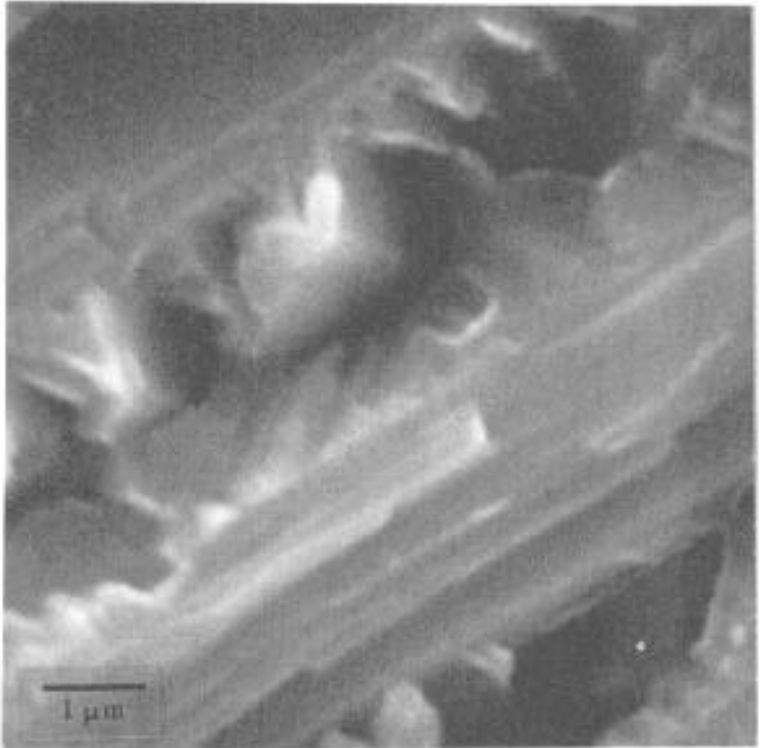

(b)

Fracture surface of 47-XD at room temperature showing (a) translamellar fracture (upper left), intergranular fracture adjacent to single phase $\gamma$ or $\beta$ grain (center) and intralemelar fracture (lower right) and (b) details of translamelar fracture showing intralamelar crack branching into the photo plane.
As $650^{\circ} \mathrm{C}$ in the $47 . \mathrm{XD}$ alloy, the fracture path was primarily translamellar with regions of transgranular fracture evident where a number of fine grains occurred. Such a region is depicted in Fig 9. Additionally, a number of $\mathrm{TiB}_{2}$ needles are apparent in these grain boundaries.

Fractographic details of cast 45-XD appeared very similar to those observed in $47 . \mathrm{XD}$ at both ambient and elevated temperatures with predominantly translamelar fracture occurring, as shown in Fig 10. Also shown is the presence of TiB2 needles lying parallel to the crack propagation path within a $\alpha_{2} /$ lamellar colony. Intergranular fracture was again noted in fine grains adjacent to prior $\alpha$ grain boundaries.

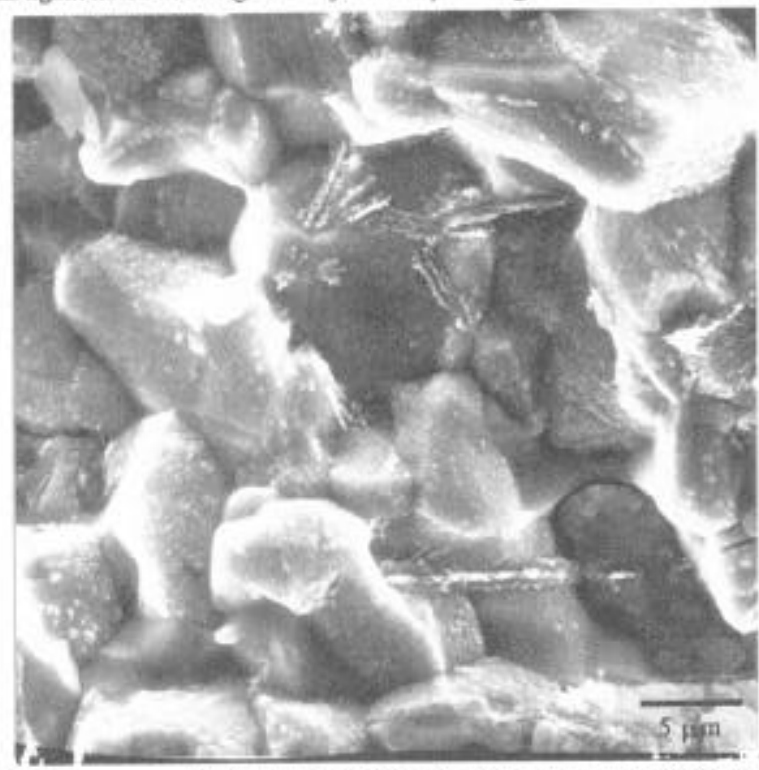

Fig. 9

Fracture surface of $47 . \mathrm{XD}$ at $650^{\circ} \mathrm{C}$ showing stightly oxidized intergranular fracture in a region of fine grains.

Compared to the cast 47-XD specimens, the wrought 47-5 fully lamellar microstructure exhibited a much coarser fracture appearance. The difference was due to the larger grain size in the wrought alloy. An apparent forging induced texture, parallel to the direction of crack propagation (perpendicular to the forging axis) was also noted. Intergranular fracture in areas of finer grains was much less common in the wrought fully lamellar microstructure. When observed, these finet grains were extremely fine and showed no evidence of lamellar structure. These grains may be grain boundary $\beta$ or $\gamma$ grains. Such grain boundary phases were observed previously in optical metallography (see Fig. 4).

Transgranular crack growth of the lamellar colonies predominated with interlamellar fracture resulting in a prominent "faceted" appearance (owing to the large $\gamma^{\prime} \alpha_{2}$ lathe colonies). Intralamellar fracture could be observed on these facets producing a distinct texture with $120^{\circ}$ symmetry (see Fig 11). The $120^{\circ}$ symmetry was composed of intralamellar fracture as detailed previously in Fig. 8.

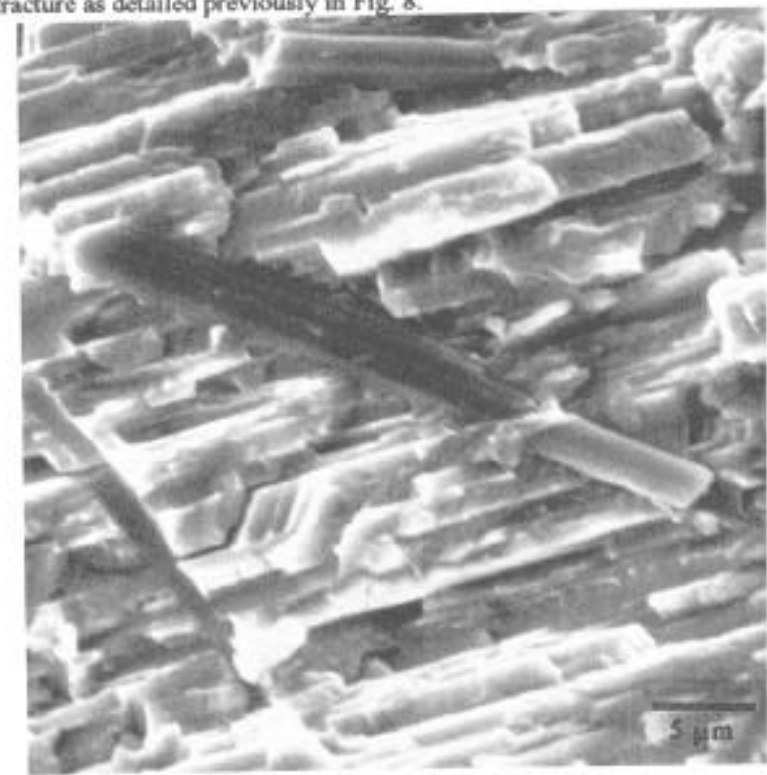

Fig. 10 Fracture surface of $45-\mathrm{XD}$ at $25^{\circ} \mathrm{C}$ showing extent of translamelar fracture with $\mathrm{TiB}_{2}$ needles. 


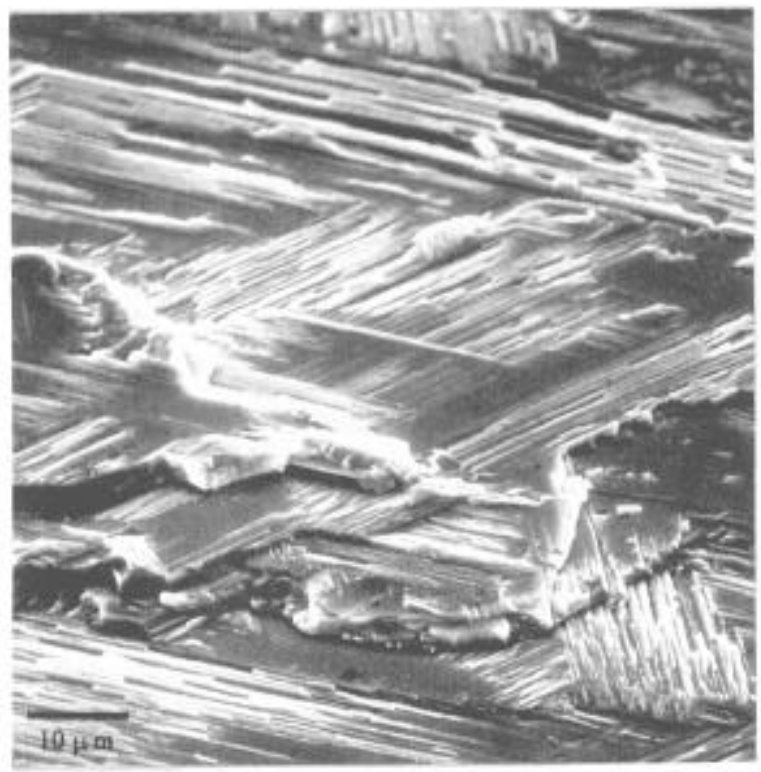

Ne. 11 Fracture surface of $47-5$ at $25^{\circ} \mathrm{C}$ showing effect of texture in mixed translamelar and intralamelar fracture.

\section{Conclusions}

It has been concluded that alloy microstructure, boride morphology and chemistry for the alloys studied here have only a second order effect in determining fatigue crack growth threshold stress intensity. Even in the case where dynamic fracture toughness is elevated as in the 47-XD alloy at $650^{\circ} \mathrm{C}$, threshold stress intersity was not significantly impacted. Through control of the $\alpha_{2} / \gamma$ colony lath size (through the introduction of $\mathrm{TiB}_{2}$ precipitates in this case), similar properties in both cast Duplex, cast Nearly Fully Lamellar and wrought Fully Lamellar alloys can be achieved. Translamellar cracking is dominant with evidence of intergranular fracture occurring adjacent to duplex a grains or refined grains of $\alpha$ or $\beta$. Much further study is needed as different researchers are reporting differing effects of microstructure on crack growth. Some of these discrepancies may be attributable to the fact that a variety of alloys have been studied that were processed under a variety of conditions.

The relatively small range between $K_{4}$ and $K_{4 C}$ leaves very little allowance for in service crack growth, therefore, design considerations will need to be nade for operation well below $K_{\text {th }}$. In order to design and fabricate structurally reliable components, new failure criteria and design guides will need to be developed. This is particularly critical in the implementation of $\gamma$-TiAl, where low densities and high threshold stress intensities hold advantage in light weight and durability not attainable in conventional nickel base alloys.

\section{References}

1. Y.-W. Kim, Acta. Metall. Mater, 40, 1121-1134 (1992).

2. Y.-W, Kim and D.M. Dimiduk, Proc. JIMIS-7 on High Temperature Deformation and Fracture, Japan Institute for Metals, Sendai, pp. 373-382 (1993)

3. Y.-W. Kim, Mat. Sci. and Eng, A193, pp. $519-533$ (1995).

4. W.O. Soboyejo, J.E. Deffeyes and P.B. Aswath, Mat. Sci. and Eng. A138, pp. 95-101 (1991).

5. D.L Davidson and J.B. Campbell, Metall. Trans., 24A. pp.1555-74 (1993).

6. S.J. Balsone, B.D. Worth, J.M. Larsen and J.W. Jones, Scripta Met. et Mat., 32, pp. 1653-58 (1995).

7. J.M. Larsen, B.D. Worth, S.J. Balsone and J.W. Jones, in Gamma Titanium Aluminides, Y-W. Kim et al. eds, TMS/ASM Int., USA (in press).

8. A.W. James and P. Bowen, Mat. Sci. and Eng. A153, Pp. 486-492 (1992).

9. K.S. Chan and D.L. Davidson, in Structural Intermetallics, R. Darolia et. al. eds. TMS, Warrendale, PA, USA, pp. 223230 (1993)

10. A.W. James and P. Bowen, in Titanium '92, F. Froes et al. eds., TMS, Warrendale, PA, USA, Pp. $1139-1146$ (1993).

11. S.J. Balsone, J.W. Jones and D.C. Maxwell, in Fatigue and Fracture of Ordered Intermetallics, W. Soboyejo et.al. eds., TMS, Warrendale, PA (1994) pp. 308-317.

12. Y. Nagakawa et.al., Japanese Inst. Metals, (1993) p. 334

13. D. Larsen et. al., in Intermetallic Motrix Composites, D. Anton et. al. eds., MRS, Pittsburgh, PA, 1990, pp. $285-92$.

14. Y-W. Kim, JOM, July (1994) pp.30-39. 